\title{
A Preliminary Digital Image Correlation Study of the Anisotropic Mechanical Properties of a 3D-Printed Mortar
}

\author{
Morgan C. Jenkins', Alexander S. Brand ${ }^{1}$, T. Trevor Painter ${ }^{1}$, and Samuel T. Sherry ${ }^{1}$ \\ ${ }^{1}$ Charles E. Via, Jr. Department of Civil and Environmental Engineering, Virginia Tech \\ 750 Drillfield Drive, Blacksburg, VA, USA, 24061 \\ morganj17@vt.edu; asbrand@vt.edu; ttrevorp@vt.edu; sher3004@vt.edu
}

\begin{abstract}
The anisotropic mechanical properties of an additive-manufactured ("3D-printed") mortar was evaluated in this study. A box geometry was printed and then sections were cut to produce beams for flexural testing in four orientations. The results demonstrate that there is a clear anisotropy in the flexural strength of 3D-printed mortar as a function of loading direction relative to the orientation of the print direction. For the mix in this study, a beam unit weight criterion was established to separate fully dense specimens from those with interior and/or exterior printing defects. Finally, preliminary digital image correlation results are presented, which demonstrate the usefulness of the technique for observing localized strain concentrations, such as generated at printing interfaces or defects.
\end{abstract}

Keywords: additive manufacturing, anisotropy, strength properties, cementitious composites

\section{Introduction}

Additive manufacturing, or "3D printing," continues to advance in civil infrastructure, particularly with the application of the technology to concrete and other cementitious composites (e.g., [1]-[6]). The seemingly exponential growth of applications [1] drives the need to develop metrology and standards for additive-manufactured cementitious composites (AMCC). This is particularly evident in the finding that AMCC exhibit anisotropic mechanical properties (e.g., [7]-[19]) owing to the directional, layer-by-layer extrusion process.

The objective of this study is to investigate the anisotropic flexural strength of an additive-manufactured mortar. The novelty of this study is the application of digital image correlation (DIC) to obtain additional data about the localized strains and displacements during a flexural test. While DIC has been applied to other 3D-printed components, such as metals and polymers [20]-[23], its usefulness to characterize AMCC has yet to be realized in the literature. In addition, this study aims to utilize existing testing ASTM standards to consider their applicability to AMCC.

\section{Experimental Methodology}

The specimens tested in this study were generated using the Sky Big Area Additive Manufacturing (SkyBAAM) system at Oak Ridge National Laboratory [24]. Specifically, a box-shaped geometry was printed (Figure 1), which was then cut and sectioned to produce various specimens. SkyBAAM is a large-scale, concrete deposition by extrusion system and is a cable-driven robot with four stations, creating a printing area within the $\mathrm{x}$ - and $\mathrm{y}$-axes and a crane controlling the $\mathrm{z}$-axis [24]. A 1.5-inch $(38 \mathrm{~mm})$ diameter extrusion nozzle was used to print a total of nine layers. The square box in Figure 1 had a side length of around 3 feet $(0.9 \mathrm{~m})$. Each layer in Figure 1 required around 97 to 100 seconds to print, resulting in a total print time of around 13 minutes.

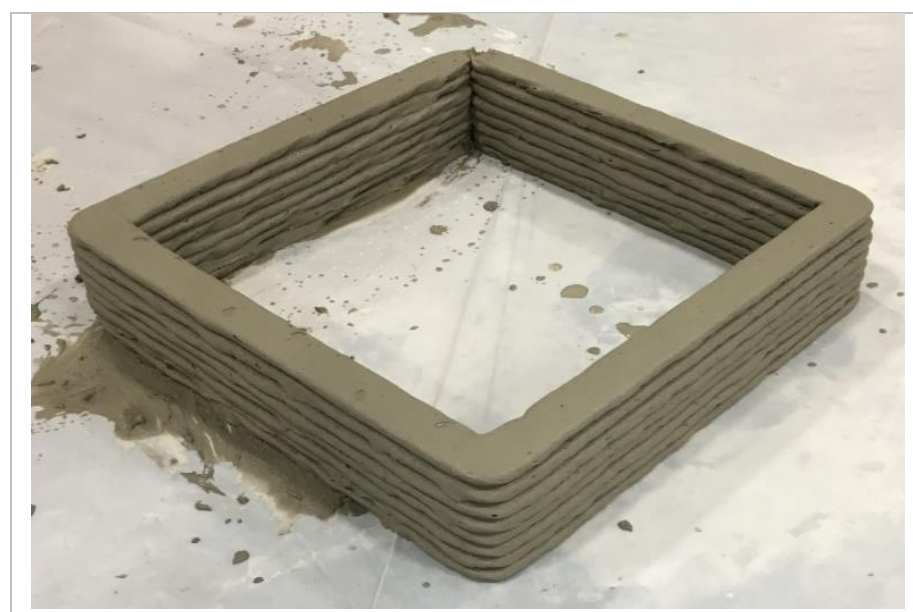

Figure 1. Box-shaped AMCC produced with SkyBAAM.

The mortar mix design followed a formulation that has been identified to yield AMCC of suitable printability [24]. The mortar mix design utilized a water-to-cementitious $(\mathrm{w} / \mathrm{cm})$ ratio of 0.375 and a sand-to-cementitious $(\mathrm{s} / \mathrm{cm})$ ratio of 1.5 . The 
total cementitious content was composed of $60 \%$ Type III portland cement, $30 \%$ ground granulated blast furnace slag, and $10 \%$ silica fume by weight. The theoretical unit weight of this mix, without air, is $140 \mathrm{pcf}(2240 \mathrm{~kg} / \mathrm{m} 3)$. In addition, a high range water reducing admixture was dosed at an approximate rate of $540 \mathrm{~mL}$ per $100 \mathrm{~kg}$ cementitious.

After the box geometry was printed, it was covered and sealed with plastic to prevent evaporation and allow for adequate curing. After at least 12 hours of curing, the corners of the box were cut, resulting in four sides that could be trimmed into smaller specimens for testing. Aside from during cutting and testing, the specimens were always sealed in plastic at ambient laboratory conditions. The sides of the AMCC box were cut to produce beam specimens for flexural testing. A total of four orientations were considered - labeled A, B, C, and D - as shown in Figure 2. Three-point bending tests were performed on these specimens. In Orientations A and B, the load was applied parallel to the layer interface and parallel and perpendicular to the print path direction for $\mathrm{A}$ and $\mathrm{B}$, respectively. In Orientations $\mathrm{C}$ and $\mathrm{D}$, the load was applied perpendicular to the print path direction and perpendicular and parallel to the layer interface for $\mathrm{C}$ and $\mathrm{D}$, respectively. Finally, all specimens were cut and trimmed to produce a rectangular cross-section for adequate flexural testing (Figure 3 ).

Preliminary three-point bending tests were performed following ASTM C348, but the loading rate was found to be too fast. Therefore, in this study, a loading rate of $150 \mathrm{psi} / \mathrm{min}$ was adopted from ASTM C293. The span length for all of the tested specimens was 4 inches $(101.6 \mathrm{~mm})$. A total of 29 specimens were tested: 7, 7, 8, and 7 for Orientations A, B, C, and $\mathrm{D}$, respectively. The age of mortar at the time of testing was around 150 days. The weight and dimensions of all specimens were collected prior to testing in order to calculate unit weights of each specimen.

For all beam bending tests, a stereo-digital image correlation (DIC) system was used, which is a tool that can be used for measuring local strains and displacements. This non-contact method optically compares a "reference" digital photo against that of other digital photos captured over the duration of testing. Prior to testing, the specimen surfaces are sprayed with a speckle pattern. These speckles can be tracked over time using stereo-DIC to determine the strains at any location on the identified surface, or region of interest; the strains are determined by the displacement of the speckles from a defined reference stage [25]. This study employed a GOM ARAMIS DIC system. Images were collected at a frequency of one per second. The DIC system consisted of a pair of 12 megapixel CMOS sensors on an $800 \mathrm{~mm}$ adjustable base manufactured by GOM. The calibration was completed with a CP40/170 calibration object supplied by GOM. This calibration had a field of view of $(320 \mathrm{~mm}, 240 \mathrm{~mm}, 240 \mathrm{~mm})$. The calibration deviation was 0.027 pixels, which is less than the acceptance criterion of $<0.07$ pixels. The equivalent size of a pixel in the field of view was $78.125 \mu \mathrm{m}$. When a strain sensitivity analysis was conducted on a series of reference photos, the max deviation observed was $916 \mu \mathrm{m} / \mathrm{m}$ and the average was $16 \mu \mathrm{m} / \mathrm{m}$.

\section{Results and Discussion 3.1 Flexural Strength}

The results from all replicate flexural tests are shown in Table 1. The mean and standard deviation values were $1290 \pm$ 412 psi, $1014 \pm 427$ psi, $1285 \pm 249$ psi, and $1214 \pm 113$ psi for Orientations A, B, C, and D, respectively. At 95\% confidence, none of the orientations are statistically different from one another by a t-test. One complication with AMCC or any additively-manufactured product, for that matter - is

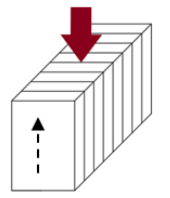

A

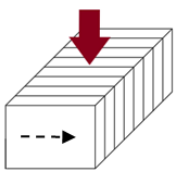

B

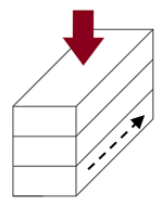

C

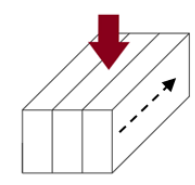

D

Figure 2. Orientations $A, B, C$, and $D$ for three-point bend tests. The large red arrow indicates the applied load location and direction. The dashed black arrow indicates the printing path direction.

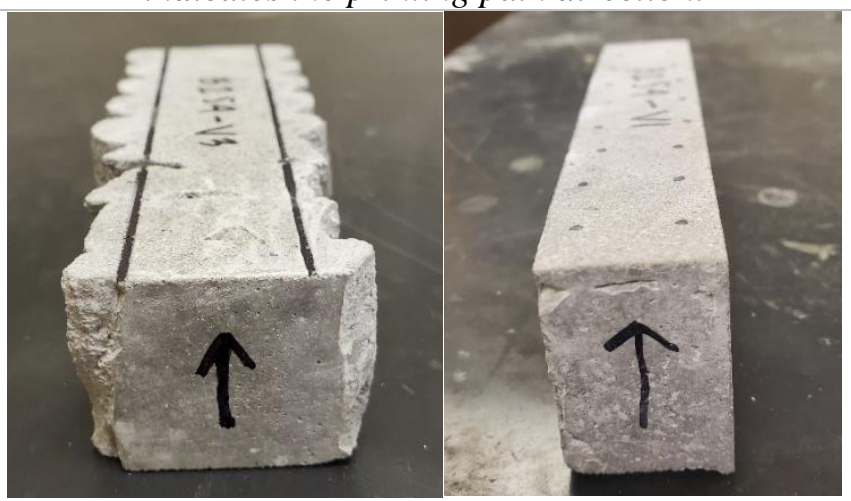

the ability to prepare consistent, fully dense components. Based on the mixture proportions, the theoretical unit weight of this mix, without air, is $140 \mathrm{pcf}\left(2240 \mathrm{~kg} / \mathrm{m}^{3}\right)$. The actual unit weight of each specimen was determined based on its mass 
and dimensions. As the measured unit weights in Table 1 are all less than 140 , it can be concluded that the mixture did contain some amount of entrapped air; since an air entraining admixture was not explicitly used, this air is likely resultant from the shearing during mixing, pumping, and extrusion [26]. In addition, some of the specimens had visible construction defects; Figure 4 shows examples of fully dense specimens and specimens with printing defects. However, not all printing defects were significant and not all printing defects appeared to affect the flexural strength. Figure 5 shows the flexural strength vs. unit weight for each replicate test, which indicates that, in general, increasing unit weights resulted in greater flexural strengths. Thus, as the measured unit weight approached the theoretical unit weight, the specimen approached a fully dense condition, thereby yielding greater strength.

Comparing the trends in Table 1 and Figure 5, Orientation D appears to be minimally influenced by the presence of printing defects. Orientations A, $\mathrm{B}$, and $\mathrm{C}$ were more influenced by the unit weight, with a clearer trend of decreasing strength with decreasing unit weights. This behavior is also evident in the relative statistical distribution in the data.

Figure 5 appears to show a greater clustering of data once the unit weight is $\geq 132 \mathrm{pcf}$. Therefore, at least for the mixture and processing in this study, a threshold of $132 \mathrm{pcf}$ is selected for sufficiently dense components (or at least dense enough to be minimally influenced by defects). The mean and standard deviation for specimens with unit weights greater than $132 \mathrm{pcf}$ were $1531 \pm 106 \mathrm{psi}, 1379 \pm 119 \mathrm{psi}, 1398 \pm 153 \mathrm{psi}$, and $1238 \pm 128 \mathrm{psi}$ for Orientations A, B, C, and D, respectively. With 95\% confidence, a t-test indicates that Orientations A and D are statistically different $(p=0.012)$ while all other orientations are not statistically different from one another.

Similarly, examining the flexural strengths for specimens with unit weights $<132 \mathrm{pcf}$, it is evident that the trends exhibit more variability. The mean and standard deviation for specimens with unit weights less than 132 pcf were $969 \pm 471 \mathrm{psi}, 741 \pm 350 \mathrm{psi}, 1030 \pm 221 \mathrm{psi}$, and $1183 \pm 107 \mathrm{psi}$ for Orientations A, B, C, and D, respectively. With 95\% confidence, none of the orientations are statistically different from one another by a t-test.

Comparing the flexural strengths corresponding to unit weights above 132 pcf with those below 132 pcf within a given orientation, Orientations A and $\mathrm{D}$ were not statistically different between the two sets with $95 \%$ confidence by a t-test. However, above and below 132 pcf, the flexural strengths were statistically different with $95 \%$ confidence by a t-test for Orientation B $(p=0.031)$ and for Orientation C $(p=0.035)$.

\subsection{Preliminary DIC Results}

The use of DIC in this preliminary study was to observe if localized strains are generated in the AMCC specimen due to manufacturing defects and/or inadequate bonding at layer interfaces. In the preliminary analysis, the location of maximum displacement and strain at failure was tracked throughout the experiment, resulting in load-displacement and stress-strain curves for each specimen. In general, after some compliance, the load-displacement behavior was fairly linear. In general, the stress-strain behavior agrees with the visual observation that Orientations A and B resulted in brittle failures with linear stress-strain trends while Orientations C and D resulted in quasi-brittle failures with nonlinear stress-strain trends. This may suggest that when AMCC is loaded parallel to the layer interface, as in Orientations A and B, the failure is sudden, owing to the failure at the interface, while when AMCC is loaded perpendicular to the layer interface, as in Orientations $\mathrm{C}$ and $\mathrm{D}$, the behavior tends more towards conventional
Table 1. Dimensions and Flexural Strengths of All Replicate Tests*

\begin{tabular}{ccc}
\hline Orientation & $\begin{array}{c}\text { Unit Weight } \\
\text { (pcf) }\end{array}$ & $\begin{array}{c}\text { Flexural } \\
\text { Strength (psi) }\end{array}$ \\
\hline A & 131.4 & 588 \\
A & 131.2 & 824 \\
A & 131.6 & 1495 \\
A & 134.6 & 1572 \\
A & 135.4 & 1553 \\
A & 133.7 & 1622 \\
A & 133.4 & 1378 \\
B & 129.2 & 771 \\
B & 131.1 & 1176 \\
B & 127.7 & 323 \\
B & 133.5 & 1437 \\
B & 130.4 & 694 \\
B & 134.0 & 1458 \\
B & 134.8 & 1242 \\
C & 134.5 & 1289 \\
C & 126.0 & 873 \\
C & 133.6 & 1558 \\
C & 136.0 & 1332 \\
C & 132.4 & 1186 \\
C & 134.7 & 1462 \\
C & 134.3 & 1561 \\
C & 131.4 & 1021 \\
\hline D & 127.5 & 1074 \\
D & 134.8 & 1285 \\
D & 134.6 & 1047 \\
D & 127.9 & 1288 \\
D & 133.6 & 1320 \\
D & 134.4 & 1298 \\
D & 127.3 & 1186 \\
\hline$*: 1 p$ & $16.0 .89 k$ \\
\hline
\end{tabular}

*Note: $1 \mathrm{pcf}=16.0 \mathrm{~kg} / \mathrm{m}^{3}, 1 \mathrm{psi}=6.89 \mathrm{kPa}$ 
mortar or concrete, which are quasi-brittle [27]. Therefore, one inference from these data is that testing in Orientations A and $\mathrm{B}$ do not yield a material property indicative of the mortar performance, but rather Orientations A and B yield an anisotropic result indicative of the interfacial layer bond. Additionally, Orientations $\mathrm{C}$ and $\mathrm{D}$ can be inferred as yielding data indicative of the mortar strength properties. Indeed, perhaps Orientation $\mathrm{C}$ can provide the most relevant indication of the mortar flexural strength, as the tensile strains are induced in a single, continuous mortar layer.

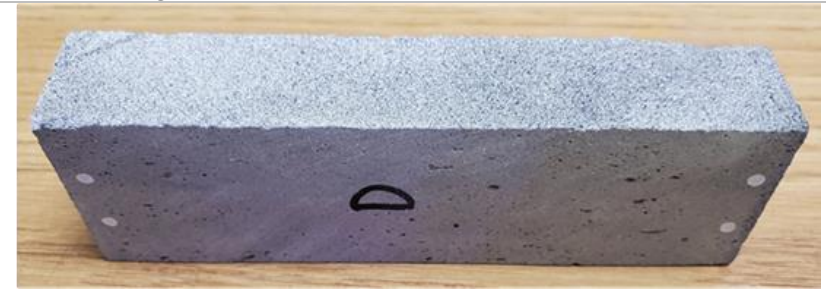

a) Orientation D, unit weight $=134.4 \mathrm{pcf}$

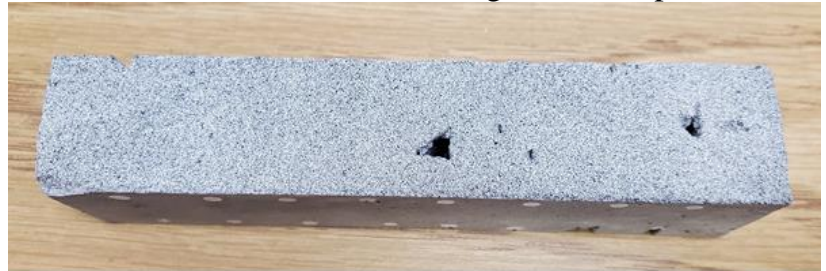

b) Orientation B, unit weight $=131.1 \mathrm{pcf}$

Figure 4. Examples of specimens that: (a) is fully and (b) has printing defects.

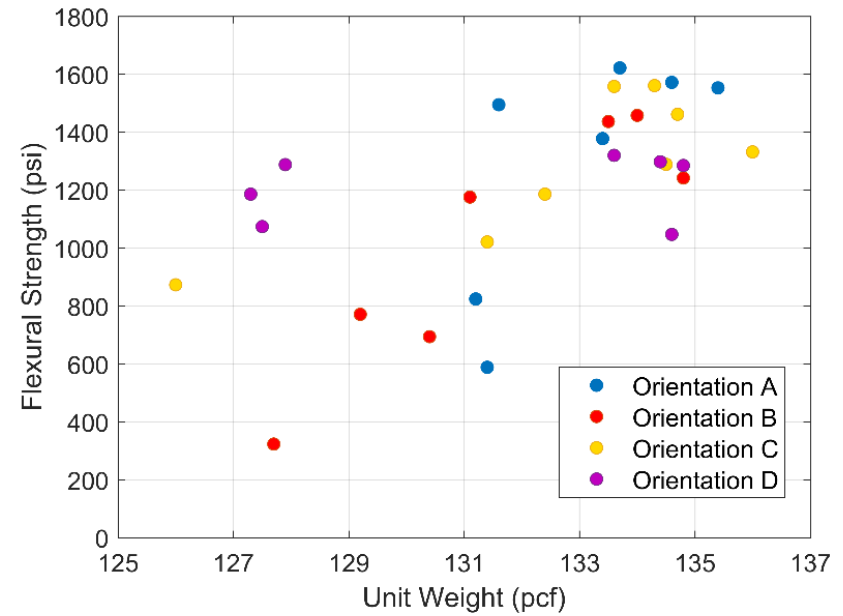

Figure 5. Flexural strength vs. unit weight for each orientation. Note: $1 \mathrm{pcf}=16.0 \mathrm{~kg} / \mathrm{m}^{3}$ and $1 \mathrm{psi}=6.89 \mathrm{kPa}$.
Using the linear portion of the load-displacement (P- $\Delta$ ) curve, the flexural modulus of elasticity $\left(\mathrm{E}_{\mathrm{F}}\right)$ was calculated according to the elastic beam equation, $\Delta=P L^{3} / 48 E_{F} I$, where $L$ is the span length and $I$ is the moment of inertia. This calculation was only performed for specimens that failed at the mid-span; otherwise, this elastic beam equation does not apply. Based on the unit weight criterion discussed in Section 3.1, only fully dense specimens with a unit weight of $\geq 132$ pcf were considered for this analysis, the results of which are shown
Table 2. Flexural Modulus of Elasticity $\left(\mathrm{E}_{\mathrm{F}}\right)$ Values Determined by DIC-Calculated Deflection

\begin{tabular}{cccc}
\hline Orientation & $\begin{array}{c}\text { Mean } \\
\text { (ksi) }\end{array}$ & $\begin{array}{c}\text { Standard } \\
\text { Deviation (ksi) }\end{array}$ & $\begin{array}{c}\text { No. of } \\
\text { Samples }\end{array}$ \\
\hline A & 856.5 & 40.8 & 2 \\
B & 858.3 & 70.5 & 3 \\
C & 430.6 & 30.7 & 6 \\
D & 644.2 & 114.1 & 4 \\
\hline
\end{tabular}

in Table 2. Orientations $\mathrm{A}$ and $\mathrm{B}$ yielded very similar $E_{F}$ results, which may be attributable to the testing orientation along the layer interface. Orientation $\mathrm{C}$ had the lowest $E_{F}$, while Orientation $\mathrm{D}$ resulted in a mean $E_{F}$ value that was moderately between the values for $\mathrm{A}$ and $\mathrm{B}$ compared to $\mathrm{C}$. These results may suggest that the interface bond has a higher flexural stiffness (Orientations A and B) than the mortar (Orientation C). The stiffness in Orientation D experiences effects from both the mortar and the interface. The modulus values in Table 2 are certainly lower than the typical static compression modulus values reported. Knowing that the elastic modulus of cement paste is lower than the elastic modulus of aggregate [28] and knowing that the composite elastic modulus tends to increase with increasing aggregate content [29], the elastic modulus can be predicted to be potentially lower for mortars than for concrete, depending on the paste and aggregate properties and contents. Furthermore, Table 2 clearly indicates an anisotropic behavior in the elastic properties of AMCC. Since cementbased composites already exhibit anisotropic elastic properties [30], it is possible that the action of manufacturing AMCC further exacerbates the anisotropic behavior. Regardless, further study is needed.

Using the DIC data, the local strains can be superimposed on the beam surface. For AMCC, DIC analysis is a powerful tool since the effects from local printing defects can be visualized. Figure 6 shows the expected progression of strain in a fully-dense AMCC beam, starting from the extreme fiber at the mid-span bottom of the beam. The behavior in Figure 6 is representative of what would be expected for conventional concrete. DIC can also demonstrate failures due to printing defects, such as the apparent strain concentrations due to printing defects in Figure 7 and Figure 8. Based on the direction of maximum strain in Figure 7 and Figure 8, the printing defects appear to be inducing a mixed mode fracture. Furthermore, 
given the reduced flexural strengths of the beams in Figure 7 and Figure 8, the printing defects resulted in a strength reduction, which may be attributable to the reduction in cross-section due to the presence of void and the strain concentrations due to the presence of defects. Therefore, coupling the flexural strength, unit weight, and DIC data can be effective strategy to evaluate the anisotropic mechanical behavior of AMCC.

\section{Conclusion}

The objective of this study was to consider the anisotropic flexural properties of a 3D-printed mortar. Flexural beams were saw-cut to produce rectangular cross-sections. Evaluating four orientations - factoring the loading direction relative to the print direction - it was found that there was significant anisotropic behavior owing to the presence of print layer interfaces and printing defects. A unit weight threshold was found to be adequate to separate defect-free from inadequately dense specimens. This unit weight segmentation was also apparently effective at assessing the flexural modulus of elasticity, which also exhibited anisotropic behavior. Using digital image correlation, preliminary analyses clearly demonstrated that printing defects can introduce localized strain concentrations, which partly explains the variability in strength properties.

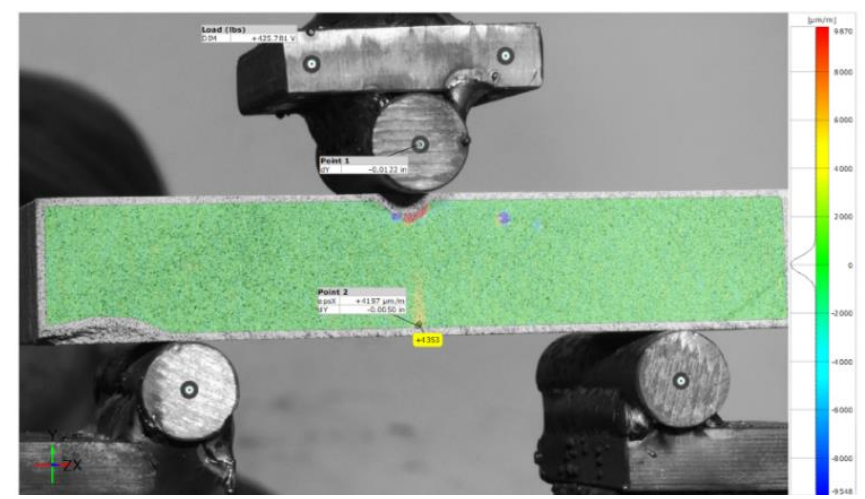

(a) $90 \%$ of the ultimate load

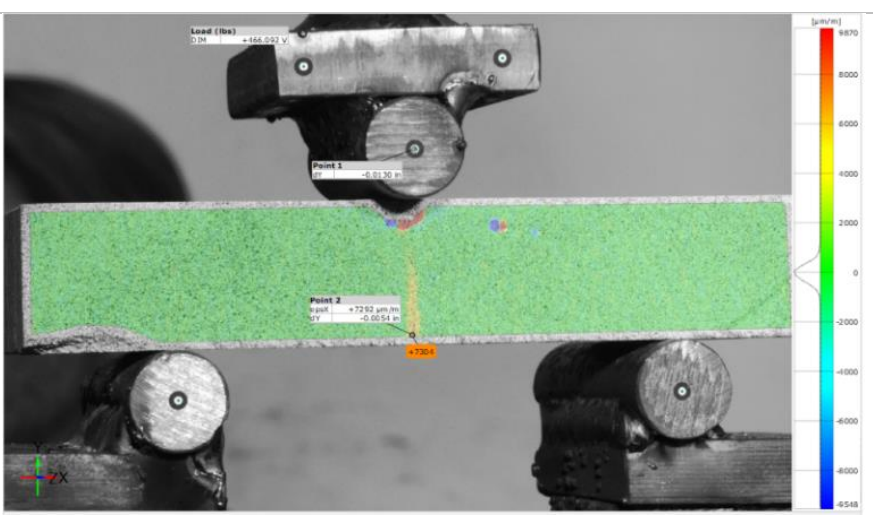

(b) $98 \%$ of the ultimate load

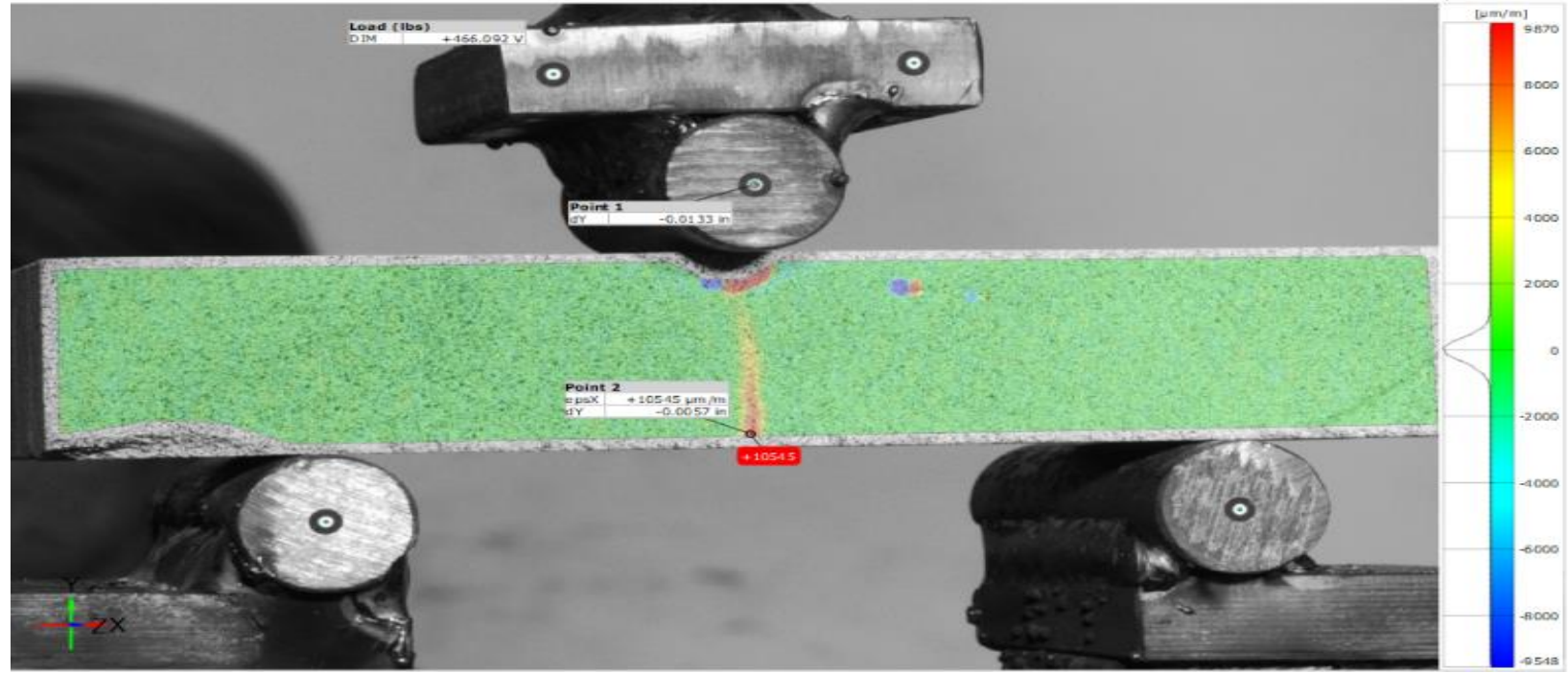

(c) at failure

Figure 6. Progression of strain for a full-dense (unit weight $=134.4 \mathrm{pcf}$ ) beam tested in Orientation $\mathrm{D}$ that failed at the mid-span. The color bar indicates tensile microstrain $(\mu \mathrm{m} / \mathrm{m})$ for strains in the $\mathrm{x}$ direction. The flexural strength was $1298 \mathrm{psi}$. 


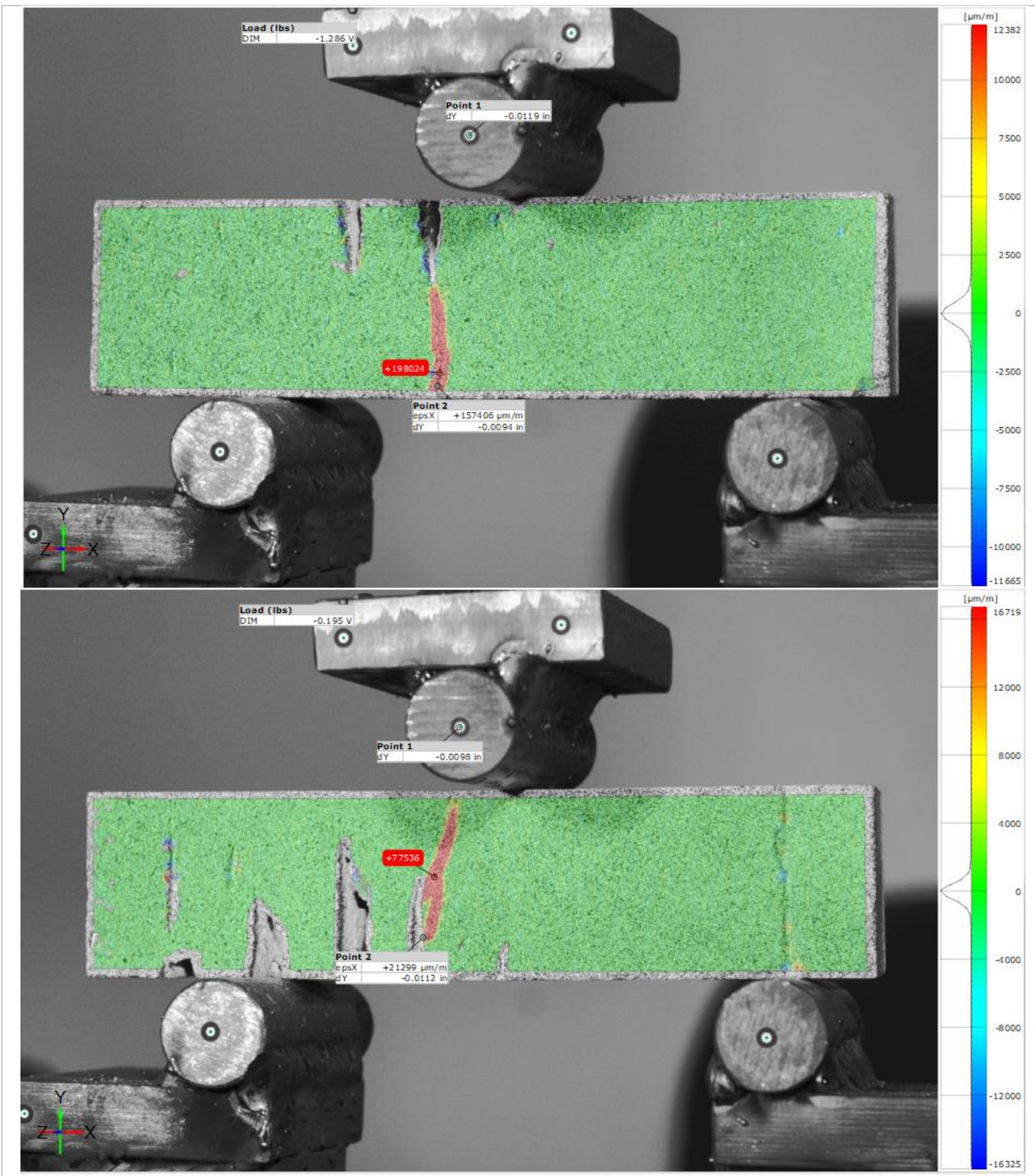

Figure 7. Strain at failure for two beams tested in Orientation A that had visible printing defects and that did not fail at the mid-span. The color bar indicates tensile microstrain $(\mu \mathrm{m} / \mathrm{m})$ for strains in the $\mathrm{x}$ direction. The unit weights and flexural strengths were $131.4 \mathrm{pcf}$ and $588 \mathrm{psi}$ (top) and $131.2 \mathrm{pcf}$ and $824 \mathrm{psi}$ (bottom), respectively. 


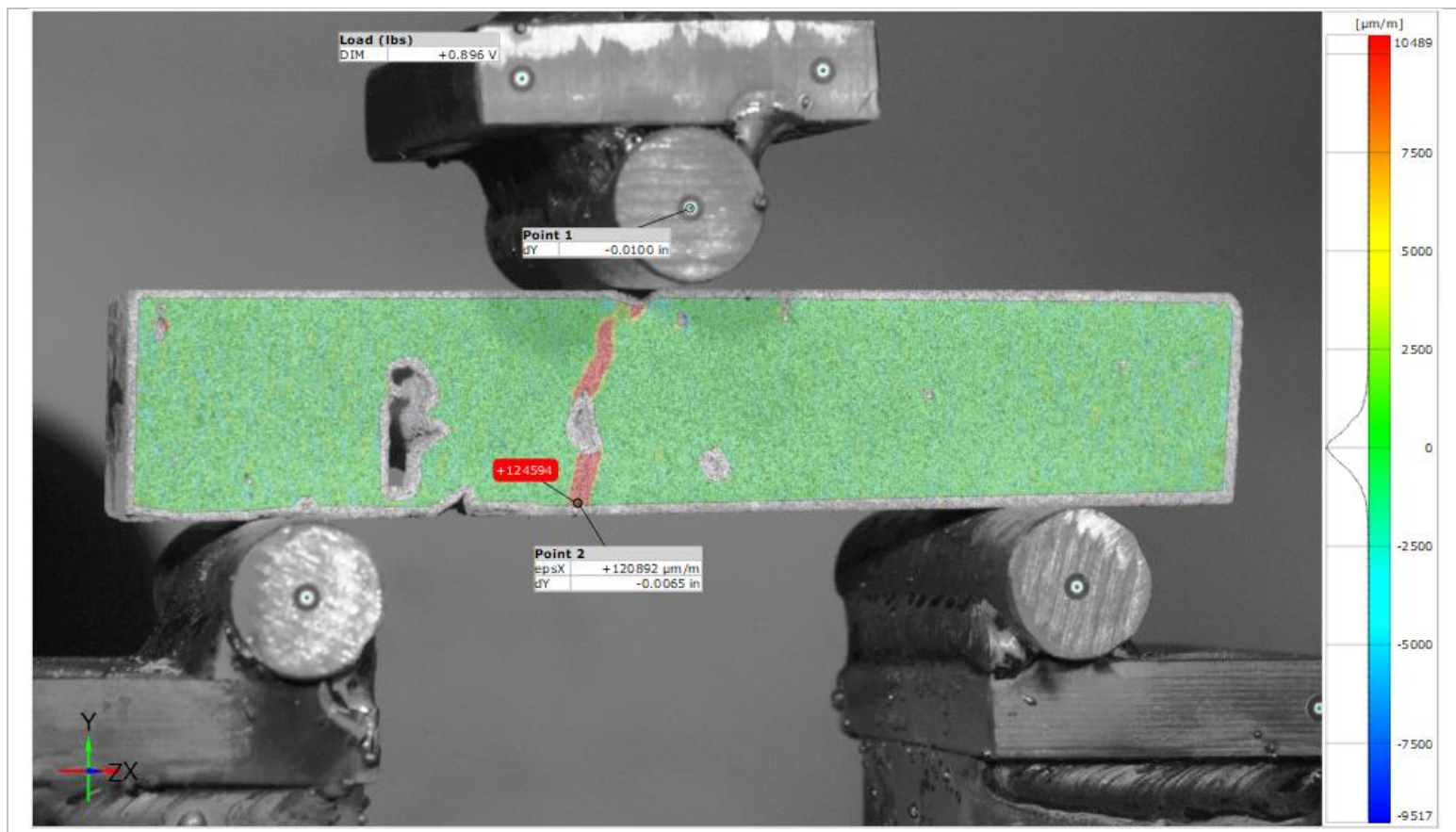

Figure 8. Strain (in the $\mathrm{x}$ direction) at failure for a beam tested in Orientation $\mathrm{B}$ that had visible printing defects (unit weight $=130.4 \mathrm{pcf}$ ) and that did not fail at the mid-span. The color bar indicates tensile microstrain $(\mu \mathrm{m} / \mathrm{m})$. The flexural strength was 694 psi.

\section{Acknowledgements}

MCJ acknowledges funding from the Via Scholars Program through the Charles E. Via, Jr. Department of Civil and Environmental Engineering at Virginia Polytechnic Institute and State University and from the Institute for Advanced Composites Manufacturing Innovation Summer Internship Program at Oak Ridge National Laboratory.

\section{References}

[1] R. A. Buswell, W. R. Leal De Silva, S. Z. Jones, and J. Dirrenberger, "3D printing using concrete extrusion: A roadmap for research," Cem. Concr. Res., vol. 112, pp. 37-49, 2018.

[2] T. Wangler, N. Roussel, F. P. Bos, T. A. M. Salet, and R. J. Flatt, "Digital concrete: A review," Cem. Concr. Res., vol. 123, p. 105780, 2019.

[3] A. Bhardwaj, S. Z. Jones, N. Kalantar, Z. Pei, J. Vickers, T. Wangler, P. Zavattieri, and N. Zou, "Additive manufacturing processes for infrastructure construction: A review," J. Manuf. Sci. Eng., vol. 141, no. 9, p. 091010, 2019.

[4] A. Paolini, S. Kollmannsberger, and E. Rank, "Additive manufacturing in construction: A review on processes, applications, and digital planning methods," Addit. Manuf., vol. 30, p. 100894, 2019.

[5] V. Mechtcherine, F. P. Bos, A. Perrot, W. R. Leal da Silva, V. N. Nerella, S. Fataei, R. J. M. Wolfs, M. Sonebi, and N. Roussel, "Extrusion-based additive manufacturing with cement-based materials - Production steps, processes, and their underlying physics: A review," Cem. Concr. Res., vol. 132, p. 106037, 2020.

[6] Z. Li, M. Hojati, Z. Wu, J. Piasente, N. Ashrafi, J. P. Duarte, S. Nazarian, S. G. Bilén, A. M. Memari, and A. Radlińska, "Fresh and hardened properties of extrusion-based 3D-printed cementitious materials: A review," Sustainability, vol. 12 , no. 14 , p. 5628, 2020.

[7] M. Hambach and D. Volkmer, "Properties of 3D-printed fiber-reinforced Portland cement paste," Cem. Concr. Compos., vol. 79, pp. 62-70, 2017.

[8] B. Panda, S. Chandra Paul, and M. Jen Tan, "Anisotropic mechanical performance of 3D printed fiber reinforced sustainable construction material," Mater. Lett., vol. 209, pp. 146-149, 2017. 
[9] P. Feng, X. Meng, J.-F. Chen, and L. Ye, "Mechanical properties of structures 3D printed with cementitious powders," Constr. Build. Mater., vol. 93, pp. 486-497, 2015.

[10] Y. Zhang, Y. Zhang, W. She, L. Yang, G. Liu, and Y. Yang, "Rheological and harden properties of the high-thixotropy 3D printing concrete," Constr. Build. Mater., vol. 201, pp. 278-285, 2019.

[11] P. Xin, Z. Wang, W. Xi, J. Peng, H. He, and R. Tang, "Building 3D printing: The anisotropy mechanical properties and printing time," in Advances in Energy and Environmental Materials, Y. Han, Ed. Singapore: Springer, 2018, pp. 535543.

[12] R. J. M. Wolfs, F. P. Bos, and T. A. M. Salet, "Hardened properties of 3D printed concrete: The influence of process parameters on interlayer adhesion," Cem. Concr. Res., vol. 119, pp. 132-140, 2019.

[13] A. V. Rahul, M. Santhanam, H. Meena, and Z. Ghani, "Mechanical characterization of 3D printable concrete," Constr. Build. Mater., vol. 227, p. 116710, 2019.

[14] G. Ma, Z. Li, L. Wang, F. Wang, and J. Sanjayan, "Mechanical anisotropy of aligned fiber reinforced composite for extrusion-based 3D printing," Constr. Build. Mater., vol. 202, pp. 770-783, 2019.

[15] G. Ma, Y. Li, L. Wang, J. Zhang, and Z. Li, "Real-time quantification of fresh and hardened mechanical property for 3D printing material by intellectualization with piezoelectric transducers," Constr. Build. Mater., vol. 241, no. 117982, 2020.

[16] T. T. Le, S. A. Austin, S. Lim, R. A. Buswell, R. Law, A. G. F. Gibb, and T. Thorpe, "Hardened properties of highperformance printing concrete," Cem. Concr. Res., vol. 42, no. 3, pp. 558-566, 2012.

[17] S. Chandra Paul, Y. W. D. Tay, B. Panda, and M. Jen Tan, "Fresh and hardened properties of 3D printable cementitious materials for building and construction," Arch. Civ. Mech. Eng., vol. 18, no. 1, pp. 311-319, 2018.

[18] V. N. Nerella, S. Hempel, and V. Mechtcherine, "Effects of layer-interface properties on mechanical performance of concrete elements produced by extrusion-based 3D-printing," Constr. Build. Mater., vol. 205, pp. 586-601, 2019.

[19] J. G. Sanjayan, B. Nematollahi, M. Xia, and T. Marchment, "Effect of surface moisture on inter-layer strength of 3D printed concrete," Constr. Build. Mater., vol. 172, pp. 468-475, 2018.

[20] X. Feng and F. Xue, "Characterization of 3D printed bolts based on digital image correlation and infrared thermography," Mater. Des., vol. 191, p. 108641, 2020.

[21] J. Karlsson, T. Sjögren, A. Snis, H. Engqvist, and J. Lausmaa, "Digital image correlation analysis of local strain fields on Ti6A14V manufactured by electron beam melting," Mater. Sci. Eng. A, vol. 618, pp. 456-461, 2014.

[22] V. Kaspar, J. Zacal, J. Rozlivka, and M. Brabec, "Tensile testing of 3D printed material with digital image correlation," in MendelNet, 2018, pp. 429-434.

[23] J. Cantrell, S. Rohde, D. Damiani, R. Gurnani, L. DiSandro, J. Anton, A. Young, A. Jerez, D. Steinbach, C. Kroese, and P. Ifju, "Experimental characterization of the mechanical properties of 3D printed ABS and polycarbonate parts," in Advancement of Optical Methods in Experimental Mechanics, S. Yoshida, L. Lamberti, and C. Sciammarella, Eds. Cham: Springer, 2017, pp. 89-105.

[24] P. C. Chesser, B. K. Post, A. C. Roschli, R. F. Lind, A. M. Boulger, L. J. Love, and K. T. Gaul, "Fieldable platform for large-scale deposition of concrete structures," in 29th Annual International Solid Freeform Fabrication Symposium, 2018.

[25] M. A. Sutton, J.-J. Orteu, and H. W. Schreier, Image Correlation for Shape, Motion and Deformation Measurements. Boston: Springer, 2009.

[26] A. Das, Y. Song, S. Mantellato, T. Wangler, R. J. Flatt, and D. A. Lange, "Influence of pumping/extrusion on the airvoid system of 3D printed concrete," in Second RILEM International Conference on Concrete and Digital Fabrication, F. Bos, S. Lucas, R. Wolfs, and T. Salet, Eds. Cham: Springer, 2020, pp. 417-427.

[27] S. P. Shah, S. E. Swartz, and C. Ouyang, Fracture Mechanics of Concrete. Wiley, 1995.

[28] S. Mindess, J. F. Young, and D. Darwin, Concrete, 2nd ed. Prentice Hall, 2003.

[29] S.-W. Cho, C.-C. Yang, and R. Huang, "Effect of aggregate volume fraction on the elastic moduli and void ratio of cement-based materials," J. Mar. Sci. Technol., vol. 8, no. 1, pp. 1-7, 2000.

[30] B. P. Hughes and J. E. Ash, “Anisotropy and failure criteria for concrete,” Mater. Struct., vol. 3, pp. 371-374, 1970. 